\title{
FORMAÇÃO DOCENTE: UM RECORTE DAS AÇÕES E AVALIAÇÃO DO PIBID/QUUIMICA DE UMA IES COMUNITÁRIA
}

\author{
Jane Herber ${ }^{1}$, José Claudio Del Pino ${ }^{2}$
}

\begin{abstract}
Resumo: O Programa Institucional de Bolsa de Iniciação à Docência - PIBID - vem se consolidando como política pública de formação docente. Tendo como meta, entre outras, inserir os licenciandos no cotidiano das escolas da rede pública de ensino. Este artigo apresenta um recorte de uma pesquisa que está sendo realizada no subprojeto PIBID/Química de uma Instituição de Ensino Superior do estado do Rio Grande do Sul. Ao considerar as metas do programa, a pesquisa tem por objetivo acompanhar e avaliar as ações dos bolsistas do referido subprojeto com a finalidade de identificar de que forma as atividades desenvolvidas contribuem com a formação docente dos envolvidos. Trata-se de uma pesquisa qualitativa e tem como abordagem metodológica o estudo de caso embasado na análise documental. Para a análise dos dados adotou-se a análise de conteúdo. Foram identificados aspectos relevantes e também foram referendadas algumas fragilidades na constante ação-reflexão-ação durante os planejamentos e ações dos bolsistas de iniciação à docência nas escolas parceiras. A partir da análise dos questionários, entrevistas e diário de bordo se identifica, nas percepções dos supervisores, os ganhos que as escolas tiveram com a aproximação da universidade por meio do PIBID, a possibilidade de metodologias diversificadas e o apoio na organização dos planejamentos de aulas. Os coordenadores de área identificam que os licenciandos que fazem parte do PIBID têm uma melhor desenvoltura quando chegam aos estágios tanto no manejo com a turma quanto nas propostas de planos de aulas. Ao finalizar percebe-se que os aspectos positivos preponderam e sem dúvida evidenciam a importância do programa como política pública de formação docente fazendo com que se reforce a necessidade de continuidade do mesmo.
\end{abstract}

Palavras-chave: Química. PIBID. Formação docente. Planejamento.

1 Doutoranda do Programa de Pós-Graduação em Educação em Ciências - Química da Vida e Saúde da Universidade Federal do Rio Grande do Sul - UFRGS. Professora da Universidade do Vale do Taquari - Univates.

2 Doutor em Química de Biomassa. Professor do Programa de Pós-Graduação em Educação em Ciências - Química da Vida e Saúde da Universidade Federal do Rio Grande do Sul - UFRGS e do Programa de Pós-Graduação em Ensino e em Ensino de Ciências Exatas da Universidade do Vale do Taquari - Univates. 


\title{
TEACHER TRAINING: A CUTTING OUT OF THE ACTIONS AND EVALUATION OF PIBID / CHEMISTRY OF A COMMUNITY HEALTH
}

\begin{abstract}
The Programa Institucional de Bolsa de Iniciação à Docência (PIBID) [Teaching Initiation Scholarship Institutional Program] has been consolidating itself as a public policy for teacher training. The Program has as a goal, among others, to include the graduates in the daily life of the public school system. This article presents a review of a research being carried out in the PIBID/Chemistry subproject of a Higher Education Institution in the state of Rio Grande do Sul, Brazil. When considering the goals of the program, the research aims to monitor and evaluate the actions of the scholarship holders of said subproject in order to identify how the developed activities contribute to the teacher formation of those involved. It is a qualitative research and has as methodological approach the case study. Data analysis was used to analyze the content. During the research process, relevant aspects of the program that have a significant impact on teacher education in Chemistry were identified and that consequently qualify the teaching and learning processes of the students of Basic Education in the schools involved. Some fragilities were also endorsed in the constant action-reflection-action during the planning and execution of such actions from the scholarship students in the partner schools. After the analysis of the questionnaires, interviews and logbooks, it's identifiable, through the perception of the supervisors, the gains that the schools had with the university's approach through PIBID, with the possibility of diversified methodologies and with the support in the organization of lesson plans. The area coordinators identify that graduates who are part of PIBID have a better disposition when they reach internships, both in the management of the class and in the proposal of class plans. At the end of the day, it is clear that the positive aspects preponderate the weaknesses and undoubtedly highlight the importance of the Program as a public policy for teacher training, thus reinforcing the need for its continuity.
\end{abstract}

Keywords: Chemistry. PIBID. Teacher formation. Planning.

\section{INTRODUÇÃO}

Tendo em vista as políticas públicas voltadas para a educação, tanto no que diz respeito à formação docente quanto à reestruturação curricular que acompanham a história da educação brasileira, é possível perceber que nas duas últimas décadas a legislação, em nível de Ministério da Educação e Cultura (MEC), vem trazendo orientações com a finalidade de melhorar a qualidade da educação. Podemos citar a Lei de Diretrizes e Bases da Educação Brasileira, Lei no9394/96, que veio aprimorar legislações que a antecedem. Posteriormente os Parâmetros Curriculares Nacionais (PCNs-1999), complementaram o aprimoramento seguido das suas reformulações, as Orientações Curriculares Nacionais (OCN-2006) e as Diretrizes Curriculares Nacionais para a Educação Básica (DCN-2012) e atualmente permeiam discussões e muitas indecisões quanto à reformulação do Ensino Médio em meios a elaboração e aprovação da Base Nacional Curricular Comum (BNCC- 2017).

Também, para a melhoria da qualidade da educação pode-se citar o Plano Nacional de Formação de Professores da Educação Básica (PARFOR), o Programa Institucional de Bolsa de Iniciação à Docência (PIBID), o Pacto Nacional pela Alfabetização na Idade Certa (Pnaic), Programa Laboratórios Interdisciplinares de Formação de 
Educadores (LIFE), como Programas da Coordenação de Aperfeiçoamento de Pessoal (Capes) vinculados ao Ministério da Educação e Cultura (MEC) voltados para a formação docente e um constante ir e vir das políticas públicas acabam, de certa forma, por fragilizar o processo de ensino e aprendizagem em nível de educação básica.

Considerando a legislação, orientações, diretrizes curriculares e a BNCC, acreditase que a formação docente de forma geral fica prejudicada, pois embora as diretrizes curriculares para os cursos de licenciatura estarem em fase de efetivação e implementação em algumas instituições de nível superior, a relação efetiva com o processo de formação de modo a atender as demandas do MEC, acabam por serem contempladas de maneira restrita nesses cursos. Também se percebe que a qualidade da educação básica está demasiadamente vinculada à formação docente sem, na maioria das vezes, considerar as condições da docência, como a infraestrutura das escolas, a valorização profissional, e as especificidades de cada estabelecimento de ensino. Principalmente ao se tratar da escola pública que vem em um processo de descendência tanto no que diz respeito à infraestrutura quanto aos processos de ensino e aprendizagem, face aos resultados apresentados das avaliações externas, destacando aqui a provinha Brasil no âmbito do Ensino Fundamental e do Exame Nacional do Ensino Médio (ENEM).

No caso específico da formação do docente de Química, enfoque desse artigo, entende-se que para educar na contemporaneidade se faz necessário que a formação contemple necessidades básicas para o exercício da docência, considerando a contextualização dos conteúdos, conhecimentos didáticos e pedagógicos, organização curricular, entre outros. Também há de se considerar que além dos aspectos didáticopedagógicos da formação profissional docente, é preciso levar em conta as condições das escolas, a infraestrutura, os recursos disponíveis, materiais didáticos. Um ambiente adequado para que o profissional possa desenvolver o seu fazer docente com um mínimo de qualidade, com segurança, que tenha a possibilidade de estar em um local em que se sinta bem, física, didática, pedagógica, emocionalmente, enfim uma escola em condições na sua totalidade.

Um dos caminhos para elevar a qualidade da educação nacional é investir na formação docente e assim sendo, o governo federal tem criado políticas públicas nacionais como o PIBID (Decreto no 7.219/2010), "com a finalidade de fomentar a iniciação à docência e melhor qualificá-la, visando à melhoria do desempenho da educação básica". Tem igualmente o objetivo de "visar ao incentivo à formação docente em nivel superior para a educação básica contribuindo para a valorização do magistério tem por metas: inserir os licenciandos no cotidiano das escolas das redes públicas de ensino, propiciando oportunidades de criação e participação em experiências metodológicas, tecnológicas e práticas docentes de caráter inovador e interdisciplinar que busquem a superação de problemas identificados no processo de ensino-aprendizagem" (Diário oficial da união, 2010).

O programa vem se firmando como política pública não somente de formação inicial, mas também de formação continuada, buscando a qualidade da formação docente, o que consequentemente acarreta a melhoria da qualidade da educação. 
Esse artigo apresenta os dados de uma pesquisa que acompanha e avalia as ações desenvolvidas por bolsistas do PIBID/Química de uma instituição de ensino superior do Rio Grande do Sul, a fim de identificar as influências do referido programa na formação atual do docente de Química, dessa IES.

\section{PERCURSO METODOLÓGICO}

A pesquisa aborda uma análise qualitativa que segundo Gray (2012) é contextual, pois é coletada em um contexto natural da vida real dos sujeitos da pesquisa, tendo como foco principal entender as formas de como as pessoas se portam e explicar suas ações sendo abertas a múltiplas interpretações. Flick (2009) aponta que as interpretações podem incluir tanto as vozes de quem está sendo estudado quanto à do pesquisador.

Para alcançar os objetivos propostos é utilizada como estratégia para a coleta de dados o estudo de caso definido por Yin (2015, p. 17) "como uma investigação empírica que investiga um fenômeno contemporâneo dentro de seu contexto da vida real, especialmente quando os limites entre o fenômeno e o contexto não estão claramente definidos".

A investigação de estudo de caso enfrenta uma situação tecnicamente diferenciada
em que existirão muito mais variáveis de interesse do que pontos de dados, e, como
resultado, conta com múltiplas fontes de evidências, com os dados precisando
convergir de maneira triangular, e, beneficia-se do desenvolvimento anterior das
proposições teóricas para orientar a coleta e a análise de dados (YIN, 2015, p. 18).

Para a análise e transcrição tanto das entrevistas como dos seminários é utilizada a análise do conteúdo que, segundo Bardin (2016, p.15), "é um conjunto de instrumentos de cunho metodológico em constante aperfeiçoamento, que se aplicam a discursos (conteúdos e continentes) extremamente diversificados". Também está sendo realizada a análise dos documentos do Programa na instituição, como o projeto institucional e os relatórios anuais do subprojeto no período de 2014 até 2017. Além da análise do Projeto Pedagógico do Curso de Licenciatura em Química da IES com a finalidade de fazer a comparação entre a teoria e a prática desenvolvida no subprojeto, principalmente quanto a prática pedagógica e o estágio docente.

Os resultados da pesquisa pretendem apontar questões relevantes a serem observadas na formação profissional docente em Química, tendo em vista as influências do PIBID e inferir que a ação-reflexão-ação da prática, um dos aspectos destacados do Programa, é essencial para a qualidade da formação profissional.

Como embasamento teórico no que diz respeito à identificação dos sujeitos da pesquisa são utilizados os módulos triádicos (ZANON, 2003): o Formador, o Professor e o Licenciando. No caso do Pibid, o formador da licenciatura, coordenador do referido 
subprojeto é o "Formador"; o professor de Química, supervisor da escola, é designado por "Professor" e os bolsistas da licenciatura são os "Licenciandos" (FIGURA 01).

Figura 01 - Triangulação entre formador, professor e licenciando

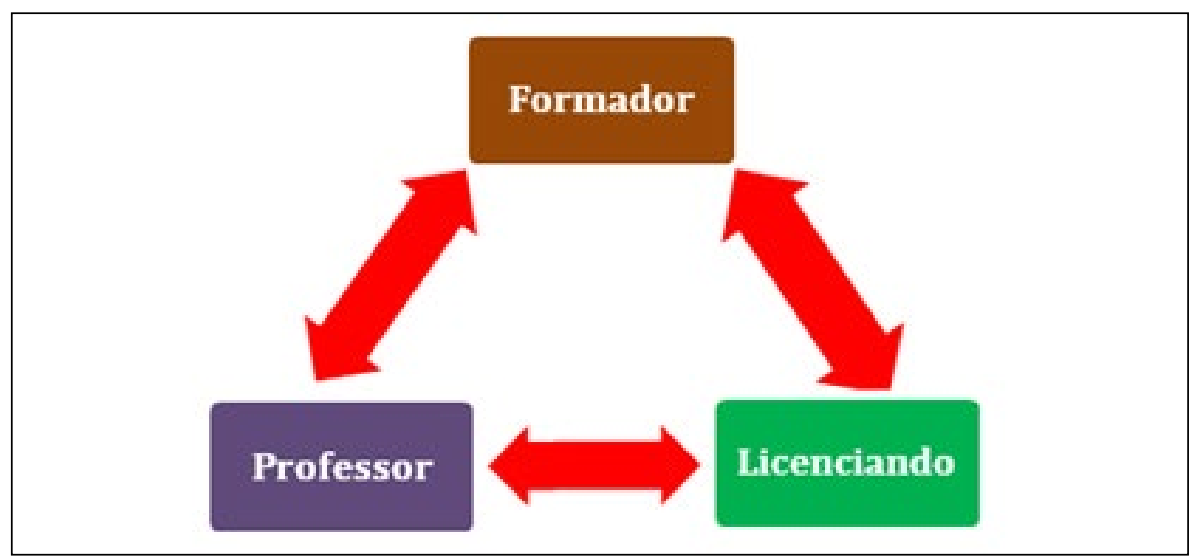

Fonte: Os autores.

A proposta prevê entrevistas a serem realizadas com a "tríade" Formador, Professor e Licenciando (ZANON, 2003), participação em seminários, o acompanhamento no planejamento e desenvolvimento das atividades de bolsistas, bem como a apreciação de relatórios apresentados pelos Licenciandos aos Professores e Formadores. Para a coleta de dados está sendo utilizado um diário de bordo e um gravador.

\section{A FORMAÇÃO DOCENTE}

\subsection{A DIRETRIZ CURRICULAR E A FORMAÇÃO DOCENTE}

Ao considerar o cenário da educação do país, percebe-se a necessidade de investir na formação do professor, pois se acredita que propostas de melhoria de qualidade de ensino são construídas pelos professores a partir da formação inicial e continuada, considerando a troca com seus pares. Atualmente existe a preocupação de um ensino de Química que seja voltado para a contextualização, o cotidiano do aluno. As Diretrizes Curriculares Nacionais - DCN (Resolução CNE/CEB no 4, de 13 de julho de 2010) apontam que os princípios pedagógicos da identidade, diversidade e autonomia, da interdisciplinaridade e da contextualização são adotados como estruturadores dos currículos. Quanto à contextualização no ensino entre outros fazeres didáticos e pedagógicos as DCN indicam que:

O desenvolvimento científico e tecnológico acelerado impõe à escola um novo posicionamento de vivência e convivência com os conhecimentos capaz de 
acompanhar sua produção acelerada. A apropriação de conhecimentos científicos se efetiva por práticas experimentais, com contextualização que relacione os conhecimentos com a vida, em oposição a metodologias pouco ou nada ativas e sem significado para os estudantes. Estas metodologias estabelecem relação expositiva e transmissivista que não coloca os estudantes em situação de vida real, de fazer, de elaborar. Por outro lado, tecnologias da informação e comunicação modificaram e continuam modificando o comportamento das pessoas e essas mudanças devem ser incorporadas e processadas pela escola para evitar uma nova forma de exclusão, a digital (BRASIL, 2010 p. 167).

As DCN destacam as questões metodológicas que precisam ser consideradas, pois as informações chegam aos estudantes de muitas maneiras, o acesso ao conhecimento e a velocidade com que esse se atualiza é significativamente veloz, e nas escolas, os docentes precisam acompanhar o avanço tecnológico propiciado pelo desenvolvimento do conhecimento buscando metodologias para tornar as aulas mais atrativas, de maneira a terem significado para os estudantes. Como indicadas:

Nessa perspectiva, são também importantes metodologias de ensino inovadoras, distintas das que se encontram nas salas de aula mais tradicionais e que, ao contrário dessas, ofereçam ao estudante a oportunidade de uma atuação ativa, interessada e comprometida no processo de aprender, que incluam não só conhecimentos, mas, também, sua contextualização, experimentação, vivências e convivência em tempos e espaços escolares e extraescolares, mediante aulas e situações diversas, inclusive nos campos da cultura, do esporte e do lazer (BRASIL, 2010, p. 181).

E para que exista contextualização, metodologias inovadoras na prática docente a DCN aponta a importância da formação docente, tanto inicial quanto continuada. É de fundamental importância aproximar não só o futuro docente, mas também os que estão na ativa das reformulações das propostas curriculares para que saibam o que precisam ensinar, e que estejam instrumentalizados para enfrentar os desafios da sala de aula. Que além da didática estejam preparados com metodologias inovadoras, que tenham a formação necessária para dominarem os conteúdos específicos de cada série/ ano a fim de ter condições de participar das decisões quanto à organização das matrizes curriculares no que diz respeito à distribuição de carga horária e conteúdos por série/ ano. Entendendo que as reuniões pedagógicas das escolas viabilizem as discussões no entorno do Plano de Trabalho da área, nesse caso das Ciências da Natureza (Química, Física, Biologia), para que esta tenha objetivos em comum, permitindo que o grupo de professores da área possa preparar suas aulas em conjunto oportunizando a interdisciplinaridade e contextualização. Seriam, no nosso entendimento, momentos de formação na escola, em que um aprende com o outro, pesquisando a sua prática e compartilhando saberes e experiências com os demais colegas. Nessa direção se entende que é possível falar em formação permanente como apresenta Imbernón (2009) que coloque o educador em processo constante de aprendizagem.

Quando o professor é pesquisador tende, a identificar os problemas da sua prática e por meio deles procurar alternativas para a qualificação da mesma. Como 
bem referencia Maldaner (2003) quanto à pesquisa do professor sobre a sua prática, que essa deve se tornar com o tempo, parte integrante de sua atividade profissional justificando-se primeiro para dentro do contexto da situação e secundariamente para outras esferas, permitindo assim evidenciar que as políticas públicas voltadas para a formação docente, tanto inicial como continuada, são necessárias para a melhoria da qualidade da educação.

\begin{abstract}
Compreender o que são os conhecimentos escolares faz-se relevante para os profissionais da educação, pois permite concluir que os ensinados nas escolas não constituem cópias dos saberes e conhecimentos socialmente produzidos. Por esse motivo, não faz sentido pensar em inserir, nas salas de aula, os saberes e as práticas tal como funcionam em seus contextos de origem. Para se tornarem conhecimentos escolares, os conhecimentos e saberes de referência passam por processos de descontextualização e recontextualização. A atividade escolar, por conseguinte, implica uma determinada ruptura com as atividades específicas dos campos de referência (MOREIRA; CANDAU, 2006; TERIGI, 1999, apud BRASIL, 2010 p. 182).
\end{abstract}

Veiga (2002) entende a formação inicial como instrumentalizadora no sentido de fornecer ao futuro professor uma sólida bagagem abrangendo a formação científica, cultural, social e pedagógica para o exercício da docência e coloca a formação continuada centrada na prática diária, nas situações vivenciadas pelo docente cotidianamente (VEIGA, 2002, p. 86).

Ainda na DCN (2010) encontra-se o indicativo do investimento, nas modalidades de cursos de Educação Profissional e Tecnológica e preconizam que as instituições educacionais precisam ser flexíveis, interdisciplinares e contextualizadoras em constante atualização de seus cursos bem como de currículos e programas com vistas a garantir a identidade, a clareza na identificação do perfil do profissional que desejam formar. Os cursos de formação precisam pensar em itinerários formativos para que os egressos possam dar continuidade aos estudos (BRASIL, 2010, p. 242) de maneira a vislumbrar que os mesmos continuem seus estudos mesmo após a graduação.

As licenciaturas pautadas na racionalidade técnica ignoram que o domínio do conteúdo de nível universitário - necessidade formativa essencial ao professor - não é suficiente para promover a aprendizagem; descuidam da sua "recontextualização" pedagógica para a escola média (ZANON, 2003). Tal fato pode ser comprovado ao se considerar que na maioria das instituições de nível superior os estudantes da licenciatura fazem disciplinas do curso de bacharelado, que contemplam uma perspectiva mais técnica, acarretando uma formação docente deficitária. Os licenciandos enfrentam problemas não somente de conteúdo, mas também de didática, de metodologias de ensino e aprendizagem que são essenciais para a instrumentalização, visando o exercício da docência.

No momento as universidades estão reformulando os currículos de modo a atender as Diretrizes Curriculares Nacionais para os Cursos de Licenciatura (2015) sendo um 
dos principais aspectos as horas destinadas a estágio e as horas destinadas à prática docente com uma forte inclinação para a teoria vinculada a prática. As diretrizes trazem que os currículos dos cursos de licenciatura precisam garantir os conteúdos específicos da respectiva área de conhecimento ou interdisciplinares, seus fundamentos e metodologias (BRASIL, 2015, p. 12) o que estão de acordo com a DCN da educação básica no que diz respeito à formação profissional docente.

Ao se deparar com a legislação vigente entende-se a necessidade da contextualização do ensino, nesse caso no ensino de Química, que vem sendo discutida em encontros de educadores de Química no âmbito nacional. Além de ser abordada em pesquisas e em artigos científicos, pois se identifica a necessidade de propor metodologias diferenciadas de ensino com a contextualização de conteúdos e interdisciplinaridade considerando a demanda atual.

\subsection{A FORMAÇÃO DO LICENCIANDO EM QUÍMICA E O PIBID}

Tendo em vista os aspectos citados anteriormente percebe-se a necessidade de investigar a formação do educador químico, visando propor alternativas para uma maior unidade na formação. Identifica-se, a partir dos currículos de alguns cursos de licenciatura, que existe uma grande disparidade nas horas de estágio de instituição para instituição e o questionamento constante dos licenciandos quanto às disciplinas compartilhadas, pois percebem a falta de critérios didáticos- pedagógicos de ensino, o que de certa forma deve ser superado a partir das reformulações dos Projetos Pedagógicos dos Cursos a partir das indicações das DCN para os cursos de licenciatura (BRASIL, 2015).

Em algumas situações os egressos têm domínio do conteúdo químico propriamente dito e têm dificuldade com a parte pedagógica, pois a didática é explorada somente no estágio (GATTI, 2011; PIMENTA, 2011; ECHEVERRIA, BENITE e SOARES, 2010; PIMENTA e LIMA, 2006), que lamentavelmente não dá conta de resolver problemas específicos da docência quando tem carga horária restrita. Também tem se observado que em alguns casos o domínio do conhecimento científico da Química tem deixado a desejar. Como afirma Maldaner (2003):

A visão epistemológica restrita e inadequada de conhecimento científico e
conhecimento químico dificulta e mesmo impede a ação eficaz dos professores
no ensino de Química. Se considerarmos ainda o fato de que os professores agem
pedagogicamente mais de acordo com o senso comum do que com as modernas
teorias de ensino e aprendizagem, por desconhecê-las na prática, não se pode
esperar resultados melhores em termos de conhecimento químico do que aqueles
sempre verificados em qualquer avaliação (MALDANER, 2003, p. 205).

Desta maneira verifica-se que a formação inicial e continuada merecem atenção especial, pois não basta o domínio de conteúdo ou o domínio da didática; o docente 
deveria conseguir fazer as articulações necessárias entre conhecimentos técnicos, teóricos e práticos a fim de refletir sobre sua prática e se tornar um professor pesquisador, procurando atualização constante e que tenha o fascínio pela profissão docente. Para tanto as políticas públicas são de grande valia para elevar a qualidade da educação, pois se acredita que uma formação de qualidade possibilita a ação-reflexão-ação viabilizando as articulações entre saberes. Assim o PIBID com a dinâmica da relação entre os seus sujeitos - formador, professor e licenciando - estão em constante formação, pois acredita-se que as ações do programa na sua amplitude contemplam tanto a formação inicial quanto a continuada, os licenciandos aprendem com os formadores e professores, é um constante aprender com e na prática. Como coloca Pimenta:

A reflexão sobre a ação das práticas se dá, “em outro nível, os saberes da experiência são também aqueles que os professores produzem no seu cotidiano docente e, em textos produzidos por outros educadores, num processo permanente de reflexão sobre a sua prática, mediatizada pela de outrem - seus colegas de trabalho. É aí que ganha a importância, na formação de professores, os processos de reflexão sobre a própria prática (PIMENTA, 1997, p. 07).

Os resultados de pesquisas realizadas por Gatti e Barreto (2009) e Gatti (2011), por exemplo, apontam as fragilidades dos estágios curriculares, que de certa forma, reforçam o que vem se identificando nas experiências na docência em cursos de licenciatura. Também indicam a necessidade de um olhar diferenciado para os projetos pedagógicos dos cursos de licenciatura quanto à descrição da operacionalização dos estágios curriculares.

\footnotetext{
Os projetos pedagógicos e as ementas dos cursos não fornecem informações sobre como eles são realizados, supervisionados e acompanhados. Não estão claros os objetivos, as exigências, formas de validação e documentação, acompanhamento, convênios com escolas das redes para a sua realização. Essa ausência nos projetos das IES e nas ementas pode sinalizar que os estágios ou são considerados como uma atividade à parte do currículo, o que é um problema, na medida em que devem se integrar com as disciplinas formativas e com aspectos da educação e da docência, ou sua realização é considerada como aspecto meramente formal (GATTI; BARRETO, 2009, p.120).
}

A pesquisa que vem sendo realizada aponta para a formação do docente em Química na Instituição de Ensino Superior - IES - investigada e as contribuições do PIBID. Tem o objetivo de investigar a formação do licenciando em Química da IES buscando identificar aspectos positivos e negativos da sua formação, considerando os contextos específicos e as influências do PIBID a fim de identificar se contribuem ou possam vir a contribuir para um melhor ensino e aprendizagem da Química na contemporaneidade.

Para iniciar a pesquisa, foi feita uma análise do estado da arte, por meio de revisão de literatura procurando fazer uma triangulação entre o PIBID, a formação docente em Química e a qualidade da educação (FIGURA 02). Também foi realizado um 
levantamento do número de alunos da licenciatura em Química na IES e quantos destes são bolsistas do Programa. Participou-se das reuniões do subprojeto Química da IES e acompanhou-se os trabalhos desenvolvidos nas escolas parceiras a fim de investigar as influências do Programa na formação atual do docente em Química, as metodologias adotadas e as dificuldades encontradas em diferentes contextos.

Figura 02 - PIBID e as relações com formação e educação

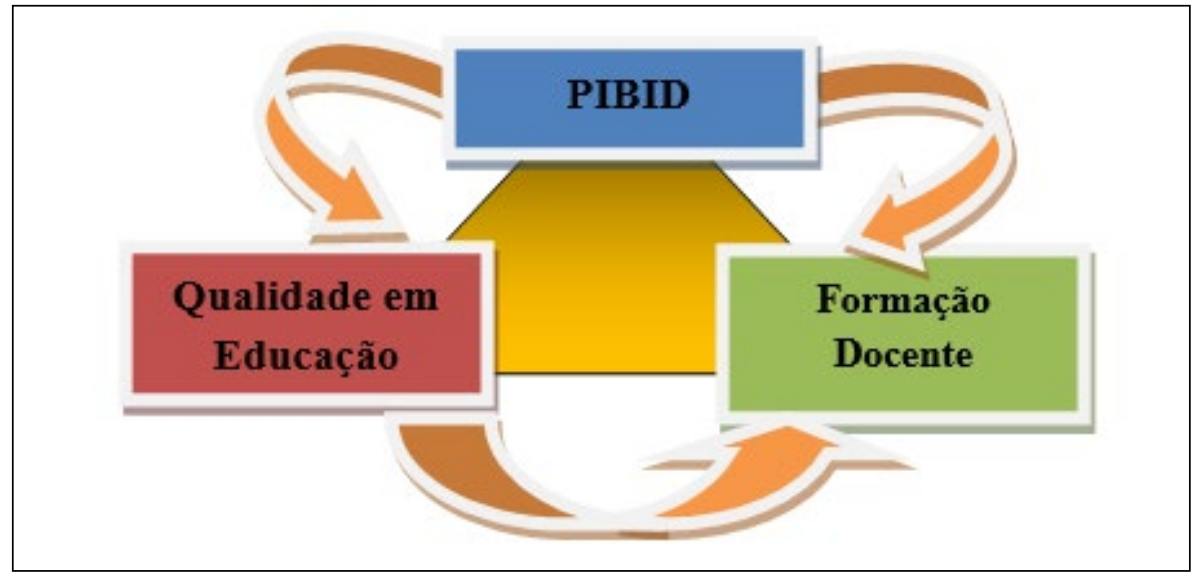

Fonte: Os autores.

A parceria entre a IES e o PIBID foi estabelecida em 2010. No edital no 11/2012 foram aprovados 12 subprojetos, entre eles o subprojeto Química, com 28 bolsistas de um total de 375, que desenvolvem atividades em 11 escolas parceiras. São coordenados por dois professores da IES e realizam atividades de iniciação à docência em diferentes níveis da escola básica.

Como a maior parte das escolas parceiras é municipal as atividades desenvolvidas são intensas nos anos finais dessa modalidade de ensino. Nas escolas com Ensino Médio os bolsistas realizam atividades de monitoria, organizam atividades de laboratório e auxiliam os professores titulares em atividades didáticas inovadoras como jogos didáticos, utilização de softwares, entre outras. Cabe destacar que alguns bolsistas estão ofertando oficinas de ciências para alunos dos Anos Iniciais, com a supervisão do professor da turma durante o período de aula e no contra turno.

\section{AS AÇÕES DO PIBID/QUÍMICA E A AVALIAÇÃO}

Por meio do acompanhamento das reuniões de avaliação do subprojeto que são organizadas pela coordenação institucional da IES, no mês de janeiro nos anos de 2015, 2016 e 2017 é possível identificar avanços e fragilidades. 
No ano de 2014, pode-se dizer que uma das maiores dificuldades enfrentadas foi a rotatividade de bolsistas nas escolas parceiras, os supervisores apontaram que quando estavam iniciando o processo de ambientação com a escola, acabavam por trocar de escola ou até mesmo, identificarem que a docência, a escolha pela licenciatura não tinha sido uma boa opção. Nesse caso se entende que as experiências com o PIBID desde o início da graduação acabam sendo um divisor de água, ou fica na licenciatura ou acaba por fazer outra graduação. Por outro lado, as experiências com as práticas docentes nas escolas parceiras, na maioria das vezes, são salutares para os bolsistas de iniciação à docência, pois se identificam com a profissão e se realizam nas experiências vivenciadas. Assim como coloca Nóvoa:

O professor é um profissional que domina a arte de reencantar, e neste aspecto, considera-se que a sua profissionalização se dá no lócus da prática educativa. A formação não se constrói por acumulação (de cursos, de conhecimentos ou de técnicas), mas sim através de um trabalho de reflexividade crítica sobre as práticas e de (re) construção (NÓVOA, 1995, p. 25).

É possível perceber que as atividades de monitoria foram intensas no ano de 2014. A gestora de uma das escolas destaca o desenvolvimento dos bolsistas no que diz respeito à constituição do ser professor, que por meio das experiências de sala de aula se tornam mais confiantes e convictos das suas ações.

Em outra escola é destacado o trabalho desenvolvido com as oficinas para os anos iniciais que iniciaram em 2014 e permaneceram tendo em vista o envolvimento das crianças que se inscrevem para participar da oficina no contra turno. Os trabalhos de iniciação científica júnior, desenvolvidos com as crianças com a pesquisa e a busca por respostas para perguntas cotidianas sobre, por exemplo, por que o céu é azul? Por que o leite derrama quando ferve? Resultaram em pesquisas realizadas pelas crianças e acompanhadas pelos bolsistas do PIBID. Mostras pedagógicas e feira de ciências foram organizadas nas escolas para que as crianças pudessem apresentar os resultados das suas pesquisas originando o livro dos 99 por quês.

Em uma reunião na escola a equipe de gestores aponta que os pais dos alunos percebem a importância da participação dos filhos nas atividades proporcionadas pelos bolsistas, também identificam que as crianças são interessadas. Uma das atividades propostas pelas licenciandas foi que as crianças em um primeiro momento fizessem perguntas do seu interesse, coisas que gostariam de saber e na sequência foi proposto que pesquisassem sobre o assunto com o auxílio das licenciandas. A atividade culminou em uma feira de ciências envolvendo os trabalhos das crianças tendo sido organizado pelas licenciandas um livro de anais da feira.

Também desenvolveram oficinas para alunos dos anos finais do ensino fundamental e do ensino médio, nesse caso para retomada de conteúdos específicos ou até mesmo voltadas para questões do ENEM. As atividades envolvem os PIBIDianos de forma 
intensa, pois nem sempre tem domínio de conteúdos e precisam estudar para executar o planejamento.

Nas reuniões semanais que acontecem na IES os formadores (coordenadores de área) auxiliam os bolsistas nos planejamentos, também indicam temas específicos envolvendo conteúdos de química para planos de aula que foram apresentados em reuniões posteriores e servirão como avaliação de disciplinas da licenciatura. Durante as apresentações os bolsistas eram questionados e tanto os coordenadores de área quanto os colegas bolsistas ID apontavam ideias, sugestões para qualificar os roteiros de aula.

As professoras (supervisoras) solicitam mais PIBIDianos nas escolas parceiras para a realização de atividades com outras turmas, identifica-se que o ensino médio, na maioria das escolas é no turno da manhã e da noite, sendo que de noite dificilmente ocorrem ações do PIBID, pois os bolsistas estudam a noite. Há uma fragilidade, pois muitos dos bolsistas moram em municípios vizinhos e dependem de transporte para chegar na escola parceira, o que acaba reduzindo o horário, pois chegam após o inicio do turno de aula e acabam saindo antes do término em função dos horários de ônibus.

A dinâmica do projeto institucional permite com que os bolsistas ID sejam supervisionados por docentes que não tenham formação específica em Química, em muitas escolas o supervisor é da área das ciências da natureza ou da coordenação pedagógica, pois todos os subprojetos PIBID da IES estão em todas as escolas parceiras, o que faz que haja um número de supervisores, e os bolsistas são distribuídos de acordo com os horários dos supervisores na escola. Todos os bolsistas cumprem horário semanal na escola parceira e na IES. Nos encontros na escola parceira, ocorre uma reunião com o supervisor para que os planos de atividades sejam explicados e sugeridos.

Como o professor nem sempre é o licenciado em química (titular da turma de aplicação) é de fundamental importância a comunicação entre o professor, o titular e o licenciando para que as ações sejam bem sucedidas. Uma das professoras diz que não abre mão dos licenciandos do subprojeto química, pois, segundo ela, funciona "super bem" no ensino fundamental, enquanto que em outra escola solicitam uma maior atenção com a organização de materiais, principalmente com o uso do laboratório. Por outro lado, as professoras de outra escola elogiam os planejamentos quanto à organização, contextualização e interdisciplinaridade que os próprios licenciandos identificam e estabelecem links com os demais componentes da área das Ciências da Natureza.

Outra atividade que se destaca são as experiências com a inclusão, pois em uma das escolas os PIBIDianos vem trabalhando com alunos deficientes visuais e preparam atividades de química específicas para esse aluno.

No ano de 2015 durante a avaliação das atividades foi destacado o número de publicações dos bolsistas, ou seja, o quantitativo de trabalhos apresentados em eventos, resultados das práticas desenvolvidas. As atividades relacionadas com oficinas se intensificaram, bem como as monitorias. Apesar da rotatividade de bolsistas, os 
mesmos acabam por ter experiências com todos os níveis da educação básica, mesmo sendo estudantes de licenciatura de química, pois existem escolas parceiras da rede municipal, as quais não ofertam o ensino médio. $O$ processo de rodízio entre as escolas vem possibilitando o reconhecimento de várias realidades e experiências didáticopedagógicas com mais de um nível e ensino. O que, em um primeiro momento, provoca estranhamento, porém os PIBIDianos destacam durante a avaliação os aspectos positivos, que preponderam os negativos. Alguns realizados com as atividades desenvolvidas com os anos iniciais, tanto que as professoras titulares acabam solicitando intervenções nas suas aulas.

Por outro lado, em uma das situações em que a professora é a titular de química não quer intervenções durante a sua aula, pois diz ter um programa a ser cumprido e não percebe como as ações podem vir a contribuir durante as suas aulas, acaba por solicitar atividades de monitoria e oficinas com temas específicos no turno oposto ao de aula, inviabilizando a participação de todos os alunos da turma.

As professoras destacam que o foco do PIBID é a formação e dizem que o programa é louvável, que veio para mexer com a escola pública, que chegou para desacomodar, que no início, nas primeiras intervenções tiveram dificuldades principalmente com os demais docentes da escola que não entendiam o programa. Para minimizar esse tipo de problema a coordenação institucional solicitou que no início de cada ano letivo as escolas organizassem um momento para receber os PIBIDianos e convidassem os demais professores para que pudessem conhecer os bolsistas e se inteirar das ações do programa.

É importante destacar que as atividades desenvolvidas com os anos iniciais e finais vêm sendo importante, pois introduzem os alunos no mundo da química desde os primeiros anos de escola, na maioria das vezes a formação da titular não contempla a área da ciência da natureza, fazendo com que, na maioria das vezes, as aulas de ciências fiquem com o enfoque da biologia. Nessas situações os bolsistas entendem que vivenciam experiências diferenciadas e que procuram fazer a transposição didática necessária para atender as demandas da série em questão. Como referencia Nóvoa:

A formação de professores deve passar para "dentro" da profissão, isto é, deve basear-se na aquisição de uma cultura profissional, concedendo aos professores mais experientes um papel central na formação dos mais jovens. A formação de professores deve valorizar o trabalho em equipa e o exercício coletivo da profissão, reforçando a importância dos projectos educativos da escola (NÓVOA, 2009, p. 87).

No ano de 2016, os cortes no número de bolsas e verbas para custeio abalaram as estruturas do programa, principalmente no que diz respeito às atividades realizadas nas escolas, pois no momento em que não foi possível inserir novos bolsistas, as vagas ociosas não foram preenchidas acarretando na diminuição no número de bolsistas e consequentemente redução de supervisores e escolas parceiras. $\mathrm{Na}$ escola de verão de 
2016 uma das maiores preocupações era com a continuidade do programa. Na plenária em que os coordenadores de área de todos os subprojetos fizeram uso da palavra destacaram-se as manifestações de necessidade de continuidade do programa tendo em vista o quantitativo de atividades realizadas nas escolas.

Além de referenciarem o envolvimento dos bolsistas, as contribuições na formação inicial bem como a viabilidade para formação continuada por meio das ações que o projeto institucional oferta continuamente ao longo do ano letivo, seja por meio de projetos de extensão, como no caso do subprojeto Química, seja por meio de oficinas e assessorias nas escolas parceiras. Foram falas intensas com muita emoção, permitindo perceber o envolvimento de todos os sujeitos com o programa. Evidenciando que:

\begin{abstract}
Os lugares da prática educativa, as escolas e outras instâncias existentes num tempo e num espaço, são o campo de atuação dos professores (os já formados e os em formação). O conhecimento e a interpretação desse real existente serão o ponto de partida dos cursos de formação, uma vez que se trata de possibilitar aos futuros professores as condições e os saberes necessários para sua atuação profissional (PIMENTA; LIMA, 2006, p.20).
\end{abstract}

A partir disso entendemos que as relações entre escola e universidade, estreitadas pelo PIBID viabilizam ações que complementam de forma significativa os estágios e as disciplinas que fazem parte dos currículos dos cursos de licenciatura, pois as aproximações entre teoria e prática vivenciadas pelos PIBIDianos acaba por fazer parte das discussões de sala de aula, possibilitando a reflexão na ação e contribuindo com a formação profissional, pois as vivências do PIBID possibilitam desenvolver processos formativos que tendem a qualificar os estágios curriculares dos envolvidos.

Outro destaque na avaliação de 2016 foi a "aceitação" do programa pelos demais professores das escolas parceiras, pois nos relatos da maioria dos bolsistas do subprojeto Química a fala foi de que estavam se sentido melhor na escola, já percebiam que os demais professores conversavam com eles e se mostravam interessados em saber mais sobre as ações do programa. De certa forma os bolsistas ID se sentiram mais acolhidos pelos demais professores. Um dos fatores que pode ter influenciado foram as reuniões de início de ano em que os gestores das escolas junto com os supervisores se organizaram para receber os bolsistas e apresentá-los para os professores da escola, momentos em que foram realizadas dinâmicas objetivando estabelecer relações interpessoais, fundamentais na época em que vivemos.

Alguns relatos dos supervisores destacaram o envolvimento dos bolsistas nas atividades propostas bem como a evolução no que se refere aos aspectos didáticos e pedagógicos. De acordo com Pimenta e Lima (2006) um curso de formação estará dando conta do aspecto prático da profissão na medida em que possibilite o treinamento em situações experimentais de determinadas habilidades consideradas, a priori, como necessárias ao bom desempenho docente (PIMENTA; LIMA, 2006). Também foi comentado sobre os bolsistas que já tinham uma graduação em Química Industrial e que 
estavam cursando licenciatura em Química e eram bolsistas do PIBID, o envolvimento destes com os demais e as atividades elaboradas com mais propriedade no que se refere a conhecimentos específicos da Química, que nem sempre que está no início do curso domina.

Os coordenadores de área indicam que o PIBID alavancou o curso de licenciatura em Química na IES, de certa forma as dificuldades enfrentadas pelos bacharéis no mercado de trabalho acabaram fazendo com que esses retornassem a IES para cursar a licenciatura na busca de outras oportunidades de trabalho.

Essas atividades, segundo os licenciandos têm significativa contribuição para sua formação docente, pois possibilitam experiências no contexto da escola, no convívio com os alunos o que antecipa aquelas que seriam desenvolvidas no estágio docente que ocorre somente a partir da metade final do curso. Além disso, contribui para a definição em termos de escolha profissional. Tardif (2002, p. 54) destaca que os saberes da experiência não são saberes como os demais, são, ao contrário, formados de todos os demais, mas retraduzidos, "polidos" e submetidos às certezas construídas na prática e na experiência. Nesse contexto entende-se que não tem como separar os saberes individuais, particularizados de cada licenciando, suas vivências e seus saberes a partir das suas experiências enquanto estudantes dos saberes adquiridos na experiência da prática docente. Acaba que cada um de nós tem um pouco dos seus professores, sua identidade se constrói a partir da experiência, das relações com os outros e com o meio. Ainda poderíamos destacar a relação com o saber da experiência, que no nosso ponto de vista vem sendo contemplado nas ações do PIBID de acordo com a reflexão de Pimenta e Lima (2006).

Observando a prática de profissionais e valendo-se de seus estudos de Filosofia, especialmente sobre John Dewey, Donald Schön propõe que a formação dos profissionais não mais se dê nos moldes de um currículo normativo que primeiro apresenta a ciência, depois a sua aplicação e por último um estágio que supõe a aplicação pelos alunos dos conhecimentos técnico- profissionais. O profissional assim formado, conforme a análise de Schön, não consegue dar respostas às situações que emergem no dia-a-dia profissional, porque estas ultrapassam os conhecimentos elaborados pela ciência, e as respostas técnicas que esta poderia oferecer ainda não estão formuladas. Valorizando a experiência e a reflexão na experiência, conforme Dewey, e o conhecimento tácito, conforme Luria e Polanyi, Schön propõe uma formação profissional baseada numa epistemologia da prática, ou seja, na valorização da prática profissional como momento de construção de conhecimento, por meio de reflexão, análise e problematização desta e o reconhecimento do conhecimento tácito, presente nas soluções que os profissionais encontram em ato (PIMENTA; LIMA, 2006, p. 15-16).

O PIBID vem gerando uma série de benefícios para as licenciaturas, desde a revitalização dos cursos até as relações entre teoria e prática vivenciadas a partir dos primeiros semestres da licenciatura. Relatórios apontam os impactos do programa e justificam a necessidade de permanência. Gatti (2013) quanto aos impactos o PIBID constata que: 
[...] o PIBID vem possibilitando, na visão de todos os envolvidos com sua realização, um aperfeiçoamento da formação inicial dos docentes para a educação básica. Em particular destacamos apreciação dos licenciandos que participam deste programa os quais declaram reiteradamente em seus depoimentos como o PIBID está contribuindo para a sua formação profissional em função de propiciar contato direto com a realidade escolar nos início de seu curso, contato com a sala e os alunos, possibilitando-lhes conhecer de perto a escola pública e os desafios da profissão docente (GATTI, 2013, p. 12).

As constatações de Gatti corroboram com as observações relatadas pelos professores nas avaliações do PIBID da IES investigada, pois permitem verificar que os acadêmicos vivenciam a utilização de metodologias diversificadas como oficinas de ciências, gincanas científicas, atividades específicas para alunos de inclusão, feiras de ciências, mostras pedagógicas, além das monitorias e aulas de reforço. Viabilizando a abordagem de conteúdos com adequação as características sócio-culturais dos estudantes, alcançando contextualização de conceitos da área de conhecimento e significação para a formação dos mesmos. Bem como possibilitando consolidar o movimento de reflexão na ação.

\section{CONSIDERAÇÕES FINAIS}

A pesquisa realizada, com base nas análises dos questionários, das entrevistas e nos registros das observações, até o momento, indica que os licenciandos em Química estão engajados com o PIBID. Nas falas dos bolsistas se percebe a motivação quando contam as atividades planejadas e a execução das mesmas nas escolas parceiras. Nas reuniões anuais de avaliação das ações do programa nas escolas parceiras os supervisores avaliam positivamente as atividades e dizem que não reconhecem mais a escola sem as ações do PIBID, pois percebem os ganhos que as escolas tiveram tanto com a aproximação da escola da universidade por meio do PIBID, a possibilidade de metodologias diversificadas e o apoio na organização dos planejamentos de aulas. Os coordenadores de área identificam que os licenciandos que fazem parte do PIBID têm uma melhor desenvoltura quando chegam aos estágios tanto no manejo com a turma quanto nas propostas de planos de aulas. O programa é um incentivo para investir na formação profissional docente, pois, no caso do PIBID da IES alguns bolsistas são formados em Química Industrial, exercem sua profissão e retornaram à instituição para cursar a licenciatura em Química.

\section{REFERÊNCIAS}

BARDIN, Laurence. Análise de conteúdo. Laurence Bardin/ tradução de Luis Antero Reto, Augusto Pinheiro. São Paulo: Edições 70, 2016. 
Disponível em: <http://www.capes.gov.br/>. Acesso em: 05 dez. 2012.

BRASIL, MINISTÉRIO DA EDUCAÇÃO, CONSELHO NACIONAL DE

EDUCAÇÃO. Portaria n. 72, de 9 de abril de 2010. Disponível em: <http://www.capes.gov. br/>. Acesso em: 05 dez. 2012. [2010]

BRASIL. Lei no 9.394, 20 de dezembro de 1996. Lei das Diretrizes e Bases da Educação Nacional. Disponível em: <www.planalto.gov.br/ccivil_03/leis/L9394.htm>. Acesso em: 14 ago. 2012.

BRASIL. Ministério da Educação Conselho Nacional de Educação Câmara de Educação Básica. Resolução no 4, de 13 de julho de 2010. Diretrizes Curriculares Nacionais Gerais para a Educação Básica. Disponível em: <http://portal.mec.gov.br/index.php?option=com content\&id=12992: diretrizes-para-a-educacao-basica>. Acesso em: 31 ago. 2016.

BRASIL, Ministério da Educação. Diretrizes curriculares nacionais para a formação inicial em nível superior. Brasília: Ministério da Educação, Secretaria da Educação Básica, 2015. Disponível em: http://portal.mec.gov.br/index.php?option=com_ docman\&view=download\&alias=70431-res-cne-cp-002-03072015-pdf\&category_ slug=agosto-2017-pdf\&Itemid=30192 . Acesso em 29 dez. 2017.

BRASIL, Ministério da Educação. Parâmetros Curriculares Nacionais: ensino médio. Secretaria de Educação Média e Tecnológica Brasília: Ministério da Educação, 1999.

BRASIL, Ministério da Educação. Orientações curriculares para o ensino médio: ciências da natureza, matemática e suas tecnologias. Brasília: Ministério da Educação, Secretaria de Educação Básica, 2006.

ECHEVERRÍA, Agustina Rosa. ZANON, Lenir Basso (Orgs.). Formação superior em Química no Brasil: práticas e fundamentos curriculares. Ijuí: Ed. Unijuí, 2010.

FLICK, Uwe. Introdução a pesquisa qualitativa. Porto Alegre: Artmed, 2009.

GATTI, Bernardete Angelina. Avaliação qualitativa dos projetos PIBID implementados em instituições de Ensino Superior - IES localizadas nas regiões Sudeste e Sul. Relatório Técnico. São Paulo: OIE/CAPES, 2013. 2v.

GATTI, Bernardete Angelina. BARRETO, Elba Siqueira de Sá. Professores do Brasil: impasses e desafios. Brasília: UNESCO, 2009. Disponível em: http://unesdoc.unesco.org/ images/0018/001846/184682por.pdf Acesso em fev. 2018.

GRAY, David E. Pesquisa no mundo real. Tradução de Roberto Cataldo Costa. 2.ed. Porto Alegre: Penso, 2012.

IMBERNÓN, Francisco. Qualidade do ensino e formação do professorado: uma mudança necessária/ Francisco Imbernón; [tradução Silvana Cobucci Leite]. São Paulo: Cortez, 2016.

IMBERNÓN, Francisco. Formação permanente do professorado: novas tendências/

Francisco Imbernón; tradução de Sandra Trabucco Valenzuela. São Paulo: Cortez, 2009. 
LEMOS, Sandra Monteiro; AZEVEDO, Gilmar de (Orgs.) Os impactos do PIBID na iniciação à docência na UERGS. Porto Alegre: Criação Humana/Evangraf, 2017.

MALDANER, Otávio Aloísio. A formação inicial e continuada de professores de química professor/pesquisador. 2.ed. ver. Ijuí : Ed. Unijuí, 2003. 424p.

MOITA, Maria da Conceição. Percursos de formação e de trans-formação. In. Vidas de Professores. NÒVOA, António (Org.). 2.ed. Portugal. Porto Editora.

NÓVOA, António. Para uma formação de professores construída dentro da profissão. Universidade de Lisboa. Portugal. Disponível em: http://www.revistaeducacion.es/ re350_09por.pdf. Acesso em dez. 2017.

NÓVOA, António (Coord.) Os professores e a sua formação. 2.ed. Lisboa: Dom Quixote, 1995.

PIMENTA, Selma Garrido (Org.). Didática e formação de professores: percursos e perspectivas no Brasil e em Portugal. 6. ed. São Paulo: Cortez, 2011.

PIMENTA, Selma Garrido; LIMA, Maria Socorro Lucena. Estágio e docência: diferentes concepções. Revista Poíesis -Volume 3, Números 3 e 4, pp.5-24, 2005/2006. Acesso em fev. 2018.

PIMENTA, Selma Garrido. Formação de professores - saberes da docência e identidade do professor. Nuances - Vol. III - Setembro de 1997. Disponível em: https:/edisciplinas.usp.br/ pluginfile.php/1287224/mod_resource/content/1/Pimenta_Form\%20de\%20profs\%20e\%20 saberes\%20da\%20docencia.pdf. Acesso em dez. 2017.

TARDIF, Maurice. Saberes docentes e formação profissional. Petrópolis, RJ: Vozes, 2002.

VEIGA, I. P. A. Professor: tecnólogo de ensino ou agente social. In: AMARAL, VEIGA (Coord.). Formação de professores: políticas e debates. 3a Ed. Campinas, SP; Papirus, 2002.

YIN, Robert K. Estudo de caso: planejamento e métodos/ Robert K. Yin; tradução:

Cristhian Matheus Herrera. - 5. ed. Porto Alegre: Bookman, 2015.

ZANON, Lenir Basso. Schnetzler, Roseli Pacheco. Elaboração conceitual de prática docente em interações triádicas na formação inicial de professores de química. IV Encontro Nacional de Pesquisa em Ciências - Bauru, SP, 2003. Disponível em: http://fep. if.usp.br/ profis/arquivos/ivenpec/Arquivos/Orais/ORAL068.pdf. Acesso em dez. 2014. 